\title{
High Rate Electrochemical Reduction of Carbon Monoxide to Ethylene using Cu-Nanoparticle-Based Gas Diffusion Electrodes
}

\author{
Lihao Han, Wu Zhou, and Chengxiang Xiang
}

ACS Energy Lett., Just Accepted Manuscript • DOI: 10.1021/acsenergylett.8b00164 • Publication Date (Web): 13 Mar 2018

Downloaded from http://pubs.acs.org on March 14, 2018

\section{Just Accepted}

"Just Accepted" manuscripts have been peer-reviewed and accepted for publication. They are posted online prior to technical editing, formatting for publication and author proofing. The American Chemical Society provides "Just Accepted" as a service to the research community to expedite the dissemination of scientific material as soon as possible after acceptance. "Just Accepted" manuscripts appear in full in PDF format accompanied by an HTML abstract. "Just Accepted" manuscripts have been fully peer reviewed, but should not be considered the official version of record. They are citable by the Digital Object Identifier (DOI®). "Just Accepted" is an optional service offered to authors. Therefore, the "Just Accepted" Web site may not include all articles that will be published in the journal. After a manuscript is technically edited and formatted, it will be removed from the "Just Accepted" Web site and published as an ASAP article. Note that technical editing may introduce minor changes to the manuscript text and/or graphics which could affect content, and all legal disclaimers and ethical guidelines that apply to the journal pertain. ACS cannot be held responsible for errors or consequences arising from the use of information contained in these "Just Accepted" manuscripts. 


\title{
High Rate Electrochemical Reduction of Carbon
}

\section{Monoxide to Ethylene Using Cu-Nanoparticle-}

\section{Based Gas Diffusion Electrodes}

\author{
Lihao Han, ${ }^{1,2}$ Wu Zhou, ${ }^{1,2}$ and Chengxiang Xiang ${ }^{1,2}$ \\ ${ }^{1}$ Joint Center for Artificial Photosynthesis, California Institute of Technology, Pasadena, CA 91125, \\ USA \\ ${ }^{2}$ Division of Chemistry and Chemical Engineering, California Institute of Technology, Pasadena, CA \\ 91125, USA
}

*To whom correspondence should be addressed: cxx@caltech.edu 


\begin{abstract}
Gas diffusion electrodes (GDEs) with high electrochemically active surface areas (ECSAs) and triple-phase boundaries for efficient gas, electron and ion transport offer a unique opportunity for high rate electrochemical $\mathrm{CO}$ reduction $(\mathrm{COR})$ in relative to traditional aqueous configurations. $\mathrm{Cu}$-nanoparticle-based GDEs were fabricated by applying a mixture of carbon powders, copper acetate aqueous solution, and Teflon onto a $\mathrm{Cu}$ gauze substrate. The catalyst-coated substrate was air-dried, mechanically pressed and subsequently annealed under forming gas to produce GDEs. Two distinctive types of GDE configurations, a flow-through configuration and a flow-by configuration, were constructed, characterized and tested to quantitatively evaluate the effects of reactant gas transport on the activity and the selectivity of the GDE materials for COR. In the flow-through configuration, a high partial current density of $50.8 \mathrm{~mA} \mathrm{~cm}{ }^{-2}$ for $\mathrm{COR}$ to $\mathrm{C}_{2} \mathrm{H}_{4}$ was achieved at $-0.85 \mathrm{~V} v s$. RHE in $10 \mathrm{M} \mathrm{KOH}$ at $-15^{\circ} \mathrm{C}$, while in the flow-by configuration with the same catalyst materials, the partial current density for $\mathrm{C}_{2} \mathrm{H}_{4}$ generation was limited to $<1 \mathrm{~mA}$ $\mathrm{cm}^{-2}$.
\end{abstract}




\section{TOC GRAPHICS}

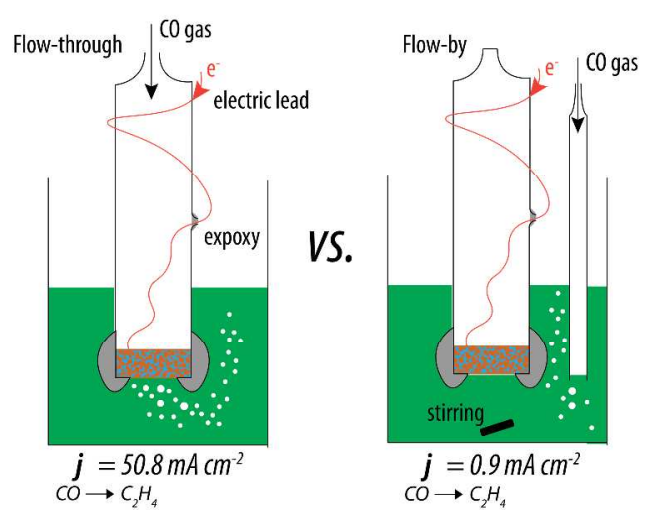


Utilizing solar energy to transform carbon dioxide $\left(\mathrm{CO}_{2}\right)$ into value-added fuels has the potential to reduce the greenhouse gas (GHG) emission and to produce sustainable fuels at large scale. Electrochemical reduction of $\mathrm{CO}_{2}$ is one of the promising approaches with near-roomtemperature operation and mild reaction conditions, ${ }^{1-9}$ however, significant challenges remain in discovering new catalyst materials and understanding fundamental reaction mechanisms for the multi-electron and multi-proton coupled reactions. Efficient, selective and stable electrocatalysts for $\mathrm{CO}_{2}$ reduction $\left(\mathrm{CO}_{2} \mathrm{R}\right)$ that involves more than two electrons and two protons, such as methanol, ethylene $\left(\mathrm{C}_{2} \mathrm{H}_{4}\right)$ and ethanol, have yet to be identified. In contrast to the poor selectivity for the higher order reduction products, many catalyst systems demonstrated efficient and selective $\mathrm{CO}_{2} \mathrm{R}$ to carbon monoxide (CO) or formate. ${ }^{10,11}$ For instance, high Faraday efficiency $(\mathrm{FE})$ and high reaction rates were reported for $\mathrm{CO}_{2} \mathrm{R}$ to $\mathrm{CO}$ in nanostructured metal dichalcogenides ${ }^{12}$ and silver electrodes ${ }^{13}$ in ionic liquids. Near-unity FE for electrochemical $\mathrm{CO}_{2} \mathrm{R}$ to formate at an operating current density of $\sim 10 \mathrm{~mA} \mathrm{~cm}^{-2}$ was also demonstrated in $\mathrm{Pd} / \mathrm{C}$ nanoparticle-based electrodes. ${ }^{14}$ Hence, one alternative strategy for efficient $\mathrm{CO}_{2} \mathrm{R}$ is to use a tandem reactor: the first catalytic reactor efficiently and selectively converts $\mathrm{CO}_{2}$ into $\mathrm{CO}$ or formate, and the second catalytic reactor converts $\mathrm{CO}$ or formate into higher-order reduction products, such as methane, ethylene and ethanol. One advantage of using the tandem strategy is that each reactor can be optimized individually in terms of electrocatalysts, electrolytes and membrane separators. For instance, high $\mathrm{pH}$ solutions are preferred electrolytes for both $\mathrm{CO}_{2} \mathrm{R}$ and carbon monoxide reduction (COR) due to the suppression of hydrogen evolution reaction (HER). However, because of the acid-base equilibrium of $\mathrm{CO}_{2}$ in the solution, the concentration of dissolved $\mathrm{CO}_{2}$ at the electrode surface quickly approached to zero in high $\mathrm{pH}$ electrolytes, ${ }^{15-17}$ which significantly limited the partial current density for $\mathrm{CO}_{2} \mathrm{R}$. Similarly, when $\mathrm{CO}_{2}$ was 
bubbled into high $\mathrm{pH}$ electrolytes in a GDE configuration, the $\mathrm{pH}$ of the solution would decrease continuously, and in many cases, the reaction rate between $\mathrm{CO}_{2}$ and the solution would be much higher than that of the desired electrochemical reduction. As a result, $\mathrm{CO}_{2} \mathrm{R}$ in high $\mathrm{pH}$ electrolytes is not a sustainable cathode reaction and would result in very low $\mathrm{CO}_{2}$ utilization in the reactor. In contrast, COR in alkaline conditions would not have those issues since CO does not react with high $\mathrm{pH}$ electrolytes.

While $\mathrm{CO}$ is one of the important intermediate species for $\mathrm{CO}_{2} \mathrm{R}$ into hydrocarbons, formate is widely considered as a dead-end product for further reduction. ${ }^{18}$ For $\mathrm{COR}, \mathrm{Cu}$ material in various forms have been investigated. ${ }^{19-22}$ Fig. 1a summarizes the performance of $\mathrm{Cu}$-based materials for COR. Various reduction products, including ethanol, acetoxy, 1-propanol, ethylene, methane, etc., were generated with FEs ranging from $0.49 \%$ to $42.42 \%$. While some notable FEs (> $40 \%$ ) for COR were demonstrated, due to the low solubility and low diffusion coefficient of CO in aqueous solution, the geometric partial current densities for COR were limited to $<1 \mathrm{~mA} \mathrm{~cm}^{-2}$. ${ }^{22}$ Fig. $1 \mathrm{~b}$ shows the calculated limiting current density for COR to ethylene or ethanol with unity $\mathrm{FE}$ as a function of hydrodynamic boundary layer thickness. Unlike $\mathrm{CO}_{2} \mathrm{R}$ in the aqueous solution, in which dissolved $\mathrm{CO}_{2}$ is replenished from the $\mathrm{CO}_{2}$ /bicarbonate equilibrium during the electrochemical reaction and the local $\mathrm{pH}$ and $\mathrm{CO}_{2}$ concentration at the electrode surface is related to the acid-base equilibrium in the electrolyte, ${ }^{15,23,24} \mathrm{COR}$ is much more straightforward as $\mathrm{CO}$ does not participate in any electrolyte reactions. The limiting current density for a planar electrode for COR simply follows the Fick's law of diffusion (Eq. 1), in which $j$ is the partial current density, $D_{0}$ and $C_{0}$ are the diffusion coefficient $\left(D_{0}=2.1 \times 10^{-9} \mathrm{~m}^{2} \mathrm{~s}^{-1}\right.$ at $\left.20{ }^{\circ} \mathrm{C}\right)$ and the solubility of $\mathrm{CO}$ in aqueous solution $\left(C_{0}=1 \mathrm{mM}\right.$ at $\left.20^{\circ} \mathrm{C}\right)$, respectively, $L$ is the hydrodynamic 
boundary layer thickness, $n$ is the number of electrons involved in the COR $(n=4$ for CO to $1 / 2$ $\mathrm{C}_{2} \mathrm{H}_{4}$ or $1 / 2 \mathrm{C}_{2} \mathrm{H}_{6} \mathrm{O}$ ), and $F$ is the Faraday constant.

$$
j=n F D_{0} \frac{C_{0}}{L}
$$

For planar systems at moderate stirring/convection conditions, the mass transport limited current densities was calculated to be $\sim 0.81 \mathrm{~mA} \mathrm{~cm}^{-2}$ at a boundary layer thickness of $\sim 100 \mu \mathrm{m}$. It is also noted that micro-structured or high surface area catalyst systems in aqueous solutions would have the same transport limitations for the attainable geometric current densities due to the overlap of the diffusion layers extended into the bulk region during operation. ${ }^{25}$ In order to achieve geometric partial current density for $\mathrm{COR}$ in the tens or hundreds of $\mathrm{mA} \mathrm{cm}{ }^{-2}$ range, an effective boundary layer thickness of $<10 \mu \mathrm{m}$ is required, which is the equivalent to the thickness of the hydrodynamic boundary layer in a rotating disk electrode (RDE) at a rotating speed of $7 \times 10^{6} \mathrm{rpm} .{ }^{25}$ As a result, a high partial current density for COR in a planar system is extremely difficult to obtain with traditional aqueous transport approaches. To circumvent the transport limitation of $\mathrm{CO}$, gas diffusion electrodes (GDEs) offer a unique opportunity to achieve high geometric current densities. The concept of a gas/vapor-fed device for electrochemical reaction, such as nitrogen reduction and $\mathrm{CO}_{2} \mathrm{R}$, can be traced back to $1980 \mathrm{~s} .{ }^{26}$ Since then, various configurations of GDEs have been employed to obtain high rates for $\mathrm{CO}_{2} \mathrm{R}$ reactions in a range of operating $\mathrm{pHs}$ and electrolytes. ${ }^{26-38}$ For instance, highly active and stable Sn-based GDEs have been reported for selective formate generation, ${ }^{27}$ and Cu-based GDEs have shown enhanced selective and activity for $\mathrm{CO}_{2} \mathrm{R}$ in mixed solvents. ${ }^{26-34}$ These GDEs often comprised of nanostructured catalyst materials with extremely high electrochemically active surface areas and the reactants were directly fed into the electrodes in the gas phase. In general, two distinctive 
types of GDEs were reported and both of which improved the operating current densities significantly. One type of GDEs utilized liquid electrolyte, such as aqueous bicarbonate electrolyte for $\mathrm{CO}_{2} \mathrm{R}$, as the proton source for electrochemical reduction, ${ }^{23,28,39}$ and the other type of GDEs directly deposited the catalyst materials onto ion-exchange membranes and utilized membrane-based electrolyte, such as Nafion, as the proton transport conduct. ${ }^{39}$

To our knowledge, COR using the GDE configuration to improve the reaction rates has yet to be demonstrated. In this work, Cu-nanoparticle-based GDEs were fabricated, tested and characterized for COR in alkaline conditions. Two distinctive types of GDE configurations, a flow-through configuration and a flow-by configuration, were constructed, characterized and compared to quantitatively evaluate the effects of reactant gas transport on the activity and selectivity of the GDE materials. We report a high $\mathrm{C}_{2} \mathrm{H}_{4}$ partial current density of $50.8 \mathrm{~mA} \mathrm{~cm}^{-2}$ at $-0.85 \mathrm{~V} v s$. RHE in $10 \mathrm{M} \mathrm{KOH}$ at $-15^{\circ} \mathrm{C}$ in a flow-through GDE configuration.

Fig. 2 shows the fabrication process of the $\mathrm{Cu}$-nanoparticle-based GDEs. The GDE fabrication process followed a previously reported recipe. ${ }^{26}$ Briefly, Slurry I containing C powders, Teflon and $\mathrm{H}_{2} \mathrm{O}$ was applied onto a $\mathrm{Cu}$ gauze substrate, air-dried and then mechanically pressed at 5000 psi (2 min) for three times (Fig.2b). Then, Slurry II containing $\mathrm{Cu}(\mathrm{Ac})_{2}$ solution, $\mathrm{C}$ powders and Teflon, was applied onto the previous C layers, air-dried and then mechanically pressed at 1000 psi ( $2 \mathrm{~min})$ for three times, and the black sample with $\mathrm{C}$ powders exhibited partly bluish as presented in Fig. 2c. Finally, the catalyst-coated substrate was annealed under the forming gas $(5 \%$ $\mathrm{H}_{2}$ in $\mathrm{N}_{2}$ ) at $325^{\circ} \mathrm{C}$ for 7 hours. The color of the catalyst-coated substrate changed from partly bluish into brown after the annealing process (Fig. 2d). The Cu-nanoparticle-based GDEs have a layer thickness of $\sim 0.1 \mathrm{~mm}$ with a $\mathrm{Cu}$ loading of $\sim 7 \mathrm{mg} \mathrm{cm}^{-2}$. The details of the experimental procedure are described in the supporting information. 
The morphology and chemical composition of the GDEs were characterized by Scanning Electron Microscope (SEM) and Energy-dispersive X-ray spectroscopy (EDX). To obtain the cross-sectional SEM image and to prevent the catalyst powders from peeling off during the characterization, the GDEs were sandwiched between two epoxy layers before slicing the cross section. Fig. 3a shows the false-colored cross-sectional SEM/EDX image of the GDE (the original SEM image is presented in Fig. S1a). The C powders (green) were pressed onto the $\mathrm{Cu}$ gauze substrate. $\mathrm{Cu}$ (purple) was found in the bulk gauze substrate and also in the nanoparticles among the $\mathrm{C}$ powders. Fig. $3 \mathrm{~b}$ shows a zoomed-in image of the $\mathrm{Cu}$-nanoparticles in the GDEs. During the mechanical pressing and the annealing process, the $\mathrm{Cu}$-nanoparticles were diffused throughout the carbon layers. High-resolution transmission electron microscopy (HR-TEM) was utilized to characterize the $\mathrm{Cu}$ particles that were peeled off from the GDEs. The average size of the $\mathrm{Cu}$ nanoparticles in GDEs was $46.56 \pm 4.61 \mathrm{~nm}$ (Fig. 3c). By further analyzing the HR-TEM images (Fig. S1b), the distance between each lattice was determined to be $0.26 \mathrm{~nm}$, which agreed well with the lattice constant of $\mathrm{Cu}$ material as a typical face-centered cubic system.

Two types of electrode configurations, a flow-through GDE configuration and a flow-by GDE configuration, were fabricated with the same GDE materials to quantitatively evaluate the effects of $\mathrm{CO}$ transport and delivery on the selectivity and activity of electrodes. In the flow-through configuration (Fig. 4a), the custom-made GDE materials with a diameter of $6 \mathrm{~mm}$ were sealed at the end of a glass tube with epoxy. All the GDEs measured in this study had a geometric surface area of $\sim 0.3 \mathrm{~cm}^{2}$. The electrical connections to the GDE materials were made by welding a flexible $\mathrm{Cu}$ wire to the $\mathrm{Cu}$ gauze substrate. The flexible $\mathrm{Cu}$ wire was weaved through the sidewall of the glass tube, while $\mathrm{CO}$ gas was introduced directly from the top of the gas tube. In the flow-by configuration (Fig. 4b), the previous gas inlet at the end of the glass tube was sealed 
with epoxy, and the $\mathrm{CO}$ gas was injected from the side inlet along with rapid stirring to provide fresh CO-saturated electrolyte flowing by the GDE surface. Fig. 4c shows the cyclic voltammetry of both electrode configurations from 0 to $-0.9 \mathrm{~V} v s$. RHE (from -0.8 to $-2.4 \mathrm{~V} v s$. $\mathrm{Ag} / \mathrm{AgCl}$ in the experiment) at a scan rate of $40 \mathrm{mV} \mathrm{s}^{-1}$ in $10 \mathrm{M} \mathrm{KOH}$. The use of the high concentration $\mathrm{KOH}$ aimed to suppress the competing HER in high $\mathrm{pH}$ electrolyte and to lower the solution resistance loss in the electrochemical cells. In addition, high concentration of $\mathrm{KOH}$ (25-30 wt.\%) is widely adopted in commercial electrolyzers to promote the ionic transport and oxygen evolution reaction (OER) at the anode chamber. ${ }^{40,41}$ For both configurations, the CO flow rate was set to $20.0 \mathrm{sccm}$. The whole cell was immersed in a cooling bath and the temperature was controlled at around $-15^{\circ} \mathrm{C}$. The uncompensated resistance $\left(R_{\mathrm{u}}\right)$ was measured using IR compensation (PEIS)-ZIR technique in a Biologic SP-300 potentiostat, and the $R_{\mathrm{u}}$ at -15 ${ }^{\circ} \mathrm{C}$ was measured to be $2.27 \Omega$. The potentials due to the IR loss in each curve in Fig. $4 \mathrm{c}$ were compensated, and the curves were smoothened using the Savitzky-Golay method in the $5^{\text {th }}$ polynomial order to reduce the noise in the raw data (Fig. S2) due to vigorous CO bubbling. The $j-V$ performances for the flow-through configuration were relatively stable during $\sim 3.5$ hours of testing, the slight increase in the total current density (also see Fig. S2a) was likely due to the increase of ECSAs as part of clogged porous channels in the initial GDEs getting cleared out during the $\mathrm{CO}$ bubbling. In contrast, relatively large increase of the total current density in the flow-by configuration was observed (also see Fig. S2b), which was likely due to the continuous increase of the wetted area and the ECSAs after immersing the electrodes in the solution. No visible catalyst loss was observed during the testing period and both configurations exhibited similar total operating current density towards the end of the testing. 
Fig. 5 shows the FE, total operating current density and partial current density for $\mathrm{COR}$ to $\mathrm{C}_{2} \mathrm{H}_{4}$ as a function of the applied voltage bias $v s$. RHE in $10 \mathrm{M} \mathrm{KOH}$ at $-15^{\circ} \mathrm{C}$. Online $\mathrm{GC}$ was connected in the electrochemical system, and was calibrated for $\mathrm{H}_{2}$ and a majority of common hydrocarbon gases (Fig. S3). The electrodes for both configurations were poised at each potential for $\sim 40 \mathrm{~min}$, and the gaseous products were detected and analyzed. In the flow-through configuration, a partial current density of $50.8 \mathrm{~mA} \mathrm{~cm}^{-2}$ and a FE of $17.8 \%$ for COR to $\mathrm{C}_{2} \mathrm{H}_{4}$ were achieved at -0.85 and $-0.74 \mathrm{~V} v s$. RHE, respectively. The observed partial current density for $\mathrm{C}_{2} \mathrm{H}_{4}$ generation was significantly higher than those reported previously. ${ }^{19-22}$ The FE for COR to $\mathrm{C}_{2} \mathrm{H}_{4}$ peaked at $-0.74 \mathrm{~V} v s$. RHE (Fig. 5a). As the applied potential increased from -0.74 V to $-0.94 \mathrm{~V} v s$. RHE, while the total operating current density increased (Fig. 5b), the FE for COR to $\mathrm{C}_{2} \mathrm{H}_{4}$ decreased significantly and the majority of the electrons contributed to HER. The dominations of HER at significant high potentials were also observed by others for both COR and $\mathrm{CO}_{2} \mathrm{R}$ in $\mathrm{Cu}$-based electrocatalysts. ${ }^{19,42,43}$

In contrast, in the flow-by configuration, the maximum partial current density and the maximum FE for $\mathrm{C}_{2} \mathrm{H}_{4}$ generation were $0.90 \mathrm{~mA} \mathrm{~cm}^{-2}$ and $0.94 \%$, respectively. The low COR current density $\left(<1 \mathrm{~mA} \mathrm{~cm}^{-2}\right)$ in the flow-by configuration agreed well with the Fick's law calculation (Fig. 1b). The majority of the reduction product was hydrogen (Fig. S4) for both configurations; liquid products from COR, such as ethanol, methanol and acetaldehyde, were also detected using a Thermo Scientific TRACE 1300 offline gas chromatography (GC). However, quantitative FEs for those liquid products were challenging to obtain in the flow-through configuration and were labeled as unknown reduction products.

The high geometric current density and high rate for COR observed in $\mathrm{Cu}$-nanoparticle-based GDEs in the flow-through configuration were originated from the high electrochemically active 
surface area (ECSA) and efficient gas, electron and ion transport at tripe phase boundaries. The ECSAs of the GDEs in the flow-through configuration were estimated using double-layer capacitance measurements in $10 \mathrm{M} \mathrm{KOH}$ (Fig. S5). ${ }^{44}$ The ECSAs of the flow-through configuration decreased gradually from 970 to $674 \mathrm{~cm}^{2}$ when the injection CO flow rate increased from 5 to $80 \mathrm{sccm}$ (Fig. S6). At higher CO flow rates (>50 sccm), delamination of catalyst materials was observed in several GDE samples and hence a moderate flow rate of 20 sccm was chosen for the study. At a flow rate of $20 \mathrm{sccm}$, the ECSA was determined to be 950 $\mathrm{cm}^{2}$, which corresponds to a roughness factor of 3167 (ratio of ECSA and geometric area). The direct gas feed in the flow-through configuration also played a critical role in improving the reaction rates. The flow-through GDEs structure contained agglomerate catalyst materials $(\mathrm{Cu}$ nanoparticle, $\mathrm{C}$ nanoparticle and polymer binders), micro-structured gas channels and electrolyte channels. During the CO injection, the agglomerate catalysts were covered with a thin layer of electrolyte that was in the equilibrium with the gas phase reactant CO. The thin electrolyte layer, in the order of hundreds of nanometers, provided efficient $\mathrm{CO}$ transport from the gas phase to the catalyst surface, while the electrolyte channels provided efficient transport and mixing for the produced hydroxides towards the bulk electrolyte during the electrochemical reaction. In contrast, although the flow-by GDE configuration had a similar ECSA, CO transport in the aqueous solution without direct gas feed limited the reaction rates for COR.

The electrochemical COR in the flow-through GDE configuration was carried out at three different temperatures. Fig. 6a shows the total current density and the corresponding FE for COR to $\mathrm{C}_{2} \mathrm{H}_{4}$ at three operating temperatures when the GDE was biased at $-2.0 \mathrm{~V} v s$. $\mathrm{Ag} / \mathrm{AgCl}$. The $R_{\mathrm{u}}$ was $2.27,1.28$ and $1.11 \Omega$, therefore, the IR-corrected applied bias was $-0.78,-0.82,-0.80 \mathrm{~V} v s$. RHE at $-15,5$ and $20^{\circ} \mathrm{C}$, respectively. The total current density decreased from $353 \pm 9 \mathrm{~mA} \mathrm{~cm}^{-2}$ 
to $212 \pm 6 \mathrm{~mA} \mathrm{~cm}^{-2}$, while the $\mathrm{FE}$ for $\mathrm{C}_{2} \mathrm{H}_{4}$ generation increased from $12.41 \pm 1.8 \%$ to $18.81 \pm 1.4 \%$, when the operating temperature of the cell decreased from $20{ }^{\circ} \mathrm{C}$ to $-15^{\circ} \mathrm{C}$. The total operating current density decreased significantly at low temperatures due to the activities of $\mathrm{Cu}$ nanoparticle-based GDE materials for HER and COR decayed exponentially as a function of the operating temperature. The reduced temperature operation in the flow-through GDE cell preferentially suppressed HER in relative to COR, which resulted in slight increase of FE for $\mathrm{C}_{2} \mathrm{H}_{4}$ generation. The stability of the $\mathrm{Cu}$-nanoparticle-based GDEs operating at high rates was also investigated. Fig. $6 \mathrm{~b}$ shows the total and partial current density and the $\mathrm{FE}$ for $\mathrm{C}_{2} \mathrm{H}_{4}$ generation as a function of the operating time when the GDEs in the flow-through configuration was poised at $-0.78 \mathrm{~V} v$. RHE electrode in $10 \mathrm{M} \mathrm{KOH}$ at $-15^{\circ} \mathrm{C}$. The $\mathrm{C}_{2} \mathrm{H}_{4}$ partial current density was stabilized in the range of 36.8 and $54.3 \mathrm{~mA} \mathrm{~cm}$, and the $\mathrm{FE}$ for $\mathrm{C}_{2} \mathrm{H}_{4}$ generation was stabilized between $13.7 \%$ and $18.4 \%$ during the first two hours of operation.

In summary, a multi-step fabrication process was developed to produce $\mathrm{Cu}$-nanoparticle-based GDEs. Two distinctive types of GDE configurations, a flow-through configuration and a flow-by configuration, were constructed, characterized and tested to quantitatively evaluate the effects of reactant gas transport on the activity and the selectivity of the catalyst materials. In a flowthrough GDE configuration, a high partial current density of $50.8 \mathrm{~mA} \mathrm{~cm}{ }^{-2}$ and a Faraday efficiency of $17.8 \%$ for COR to $\mathrm{C}_{2} \mathrm{H}_{4}$ were achieved at -0.85 and $-0.74 \mathrm{~V}$ vs. RHE in $10 \mathrm{M} \mathrm{KOH}$, respectively. The high ECSAs, direct gas feed configuration and triple-phase boundaries for efficient gas, electron and ion transport significantly enhanced the reaction rates of the catalyst materials for COR. In contrast, when the same catalyst materials were constructed in a flow-by GDE configuration, the partial current density for COR to $\mathrm{C}_{2} \mathrm{H}_{4}$ was limited to $<1 \mathrm{~mA} \mathrm{~cm}{ }^{-2}$ due to the low solubility and diffusion coefficient of $\mathrm{CO}$ in aqueous solution. Direct gas feed 
configurations provided a unique electrode structure for efficient and stable electrochemical reactions without mass transport limitations, especially for gases with low solubility in aqueous solutions, such as $\mathrm{CO}, \mathrm{CO}_{2}$ and $\mathrm{N}_{2}$. 

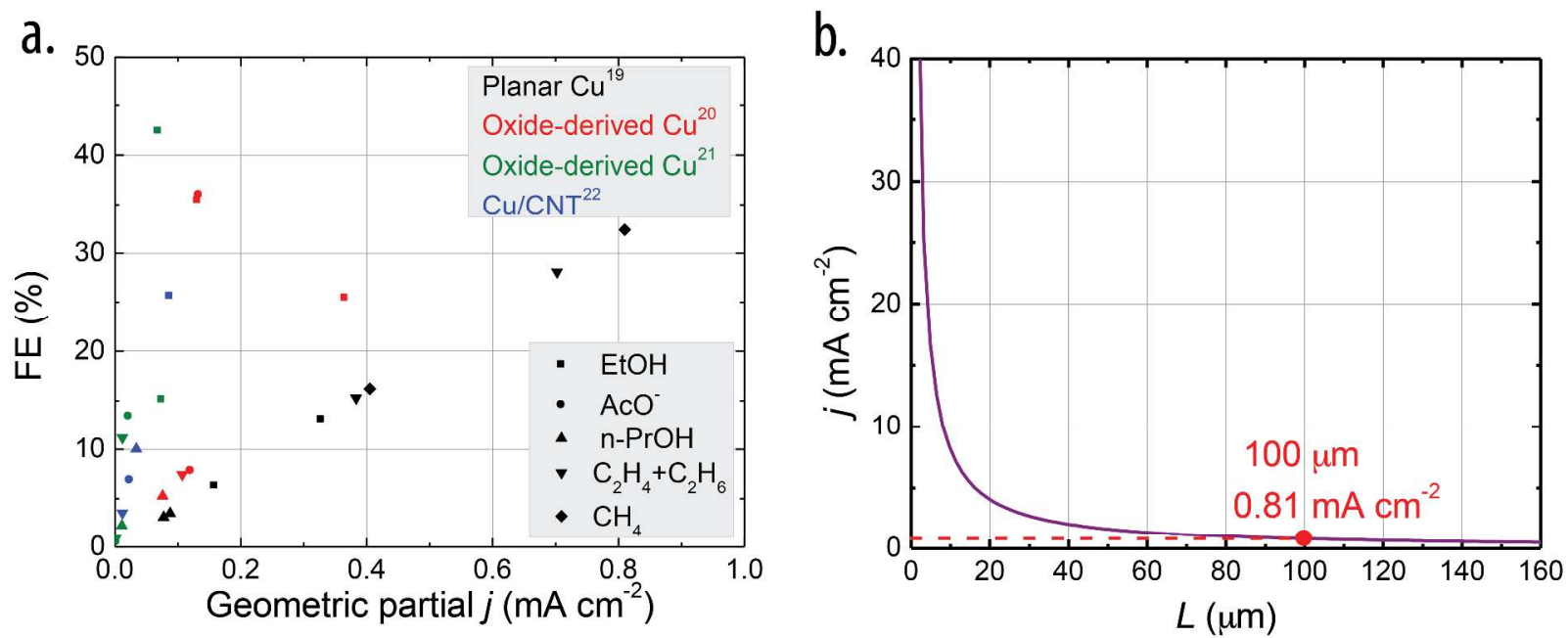

Figure 1. (a) The partial current density vs. the Faraday efficiency for COR reported in literature. (b) Simulated limiting current density for COR to $\mathrm{C}_{2} \mathrm{H}_{4}$ or $\mathrm{C}_{2} \mathrm{H}_{6} \mathrm{O}$ at unity $\mathrm{FE}$ as a function of hydrodynamic boundary layer thickness based on Fick's law of diffusion. 
a.

\section{Cu gauze substrate}

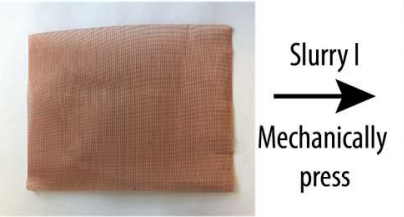

b. C-nanoparticle coated electrode

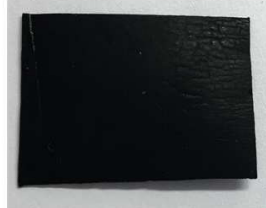

c.

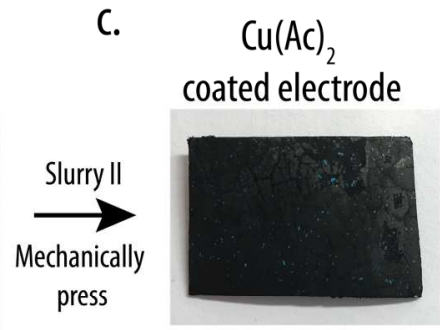

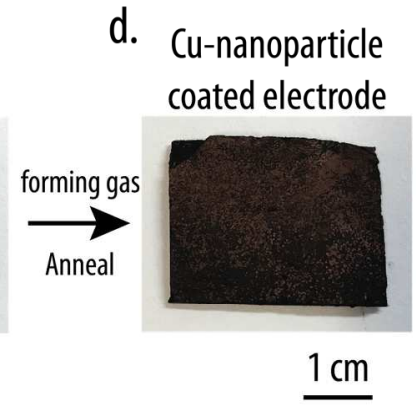

d. Cu-nanoparticle

Figure 2. The fabrication process for $\mathrm{Cu}$-nanoparticle-based GDEs: (a) $\mathrm{Cu}$ gauze was used as the substrate; (b) Slurry I containing carbon powders, Teflon and water was applied onto the $\mathrm{Cu}$ gauze substrate, and mechanically pressed after dried in air; (c) Slurry II containing carbon powders, Teflon and copper acetate solution was applied onto the previous layers, and mechanically pressed after dried in air; (d) Cu nanoparticles were formed when the copper acetate in the sample was reduced in forming gas at $325^{\circ} \mathrm{C}$ for 7 hours. 


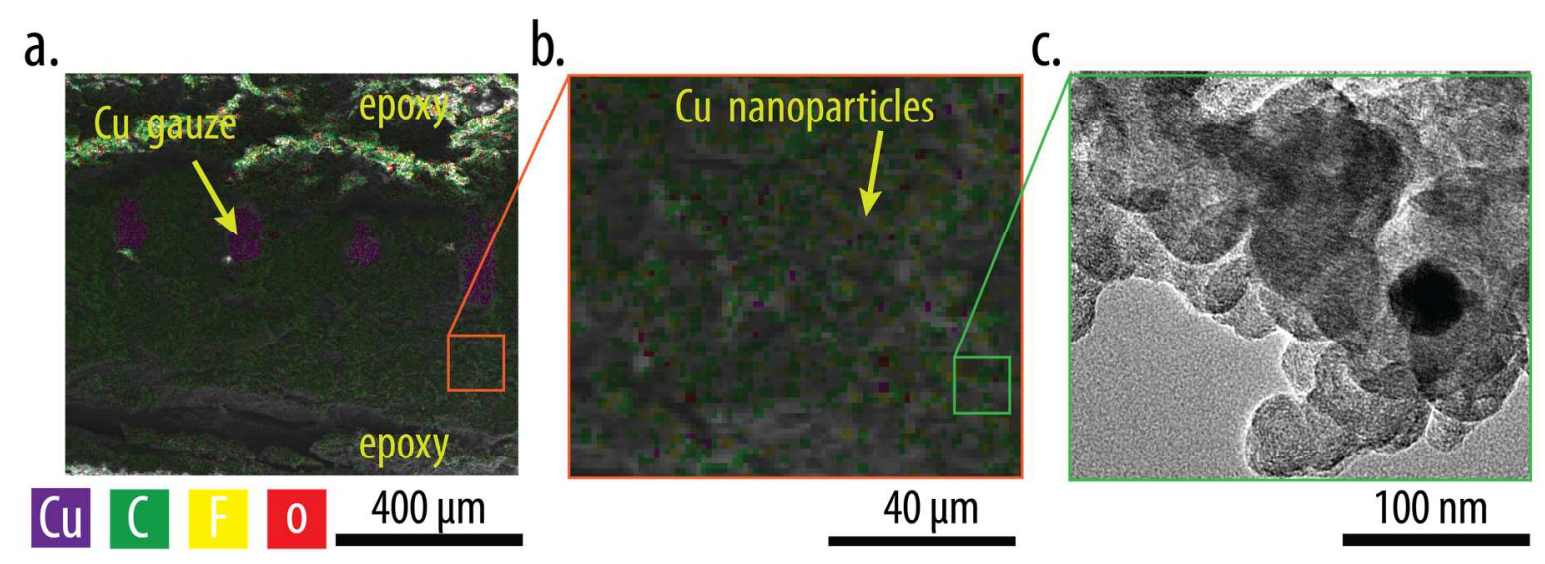

Figure 3. The cross-sectional SEM images with elemental mapping (a-b) and the HR-TEM image (c) of Cu-nanoparticle-based GDEs. 
a.

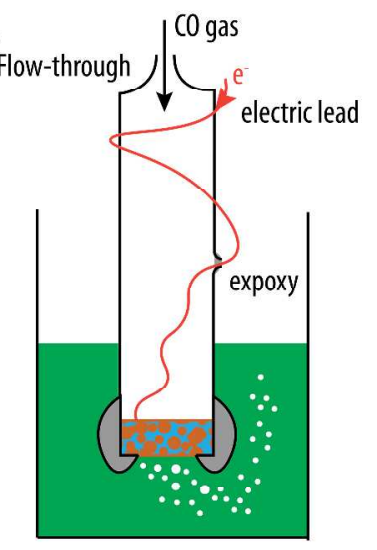

b.

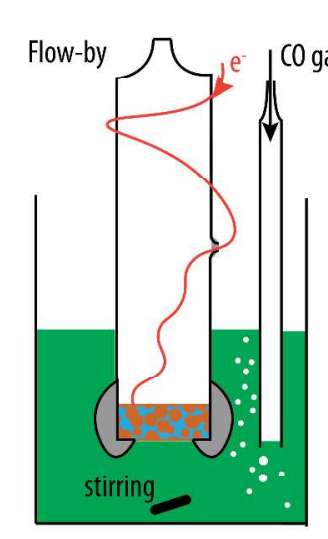

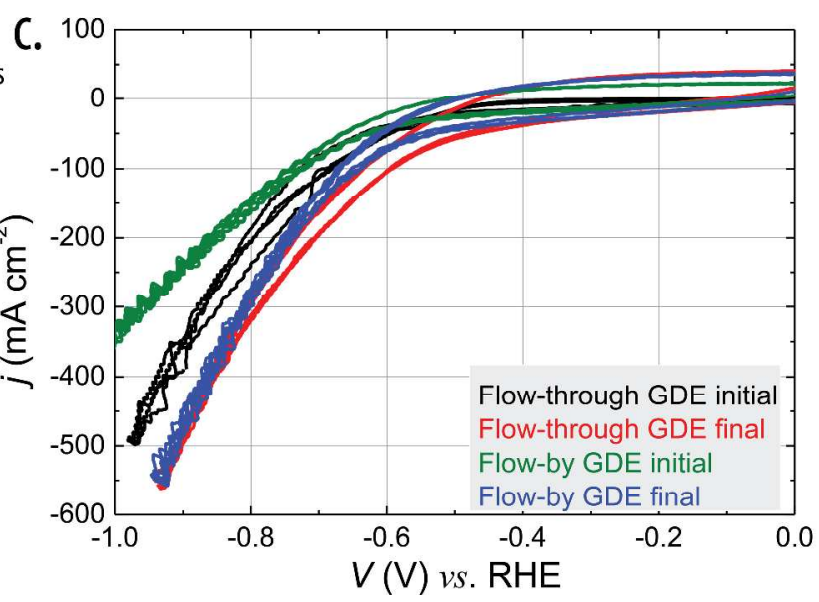

Figure 4. A schematic illustration of the GDE materials in the flow-through configuration (a) and in the flow-by configuration (b). The cyclic voltammetry for both configurations before and after 3.5 hours of operation (c). 


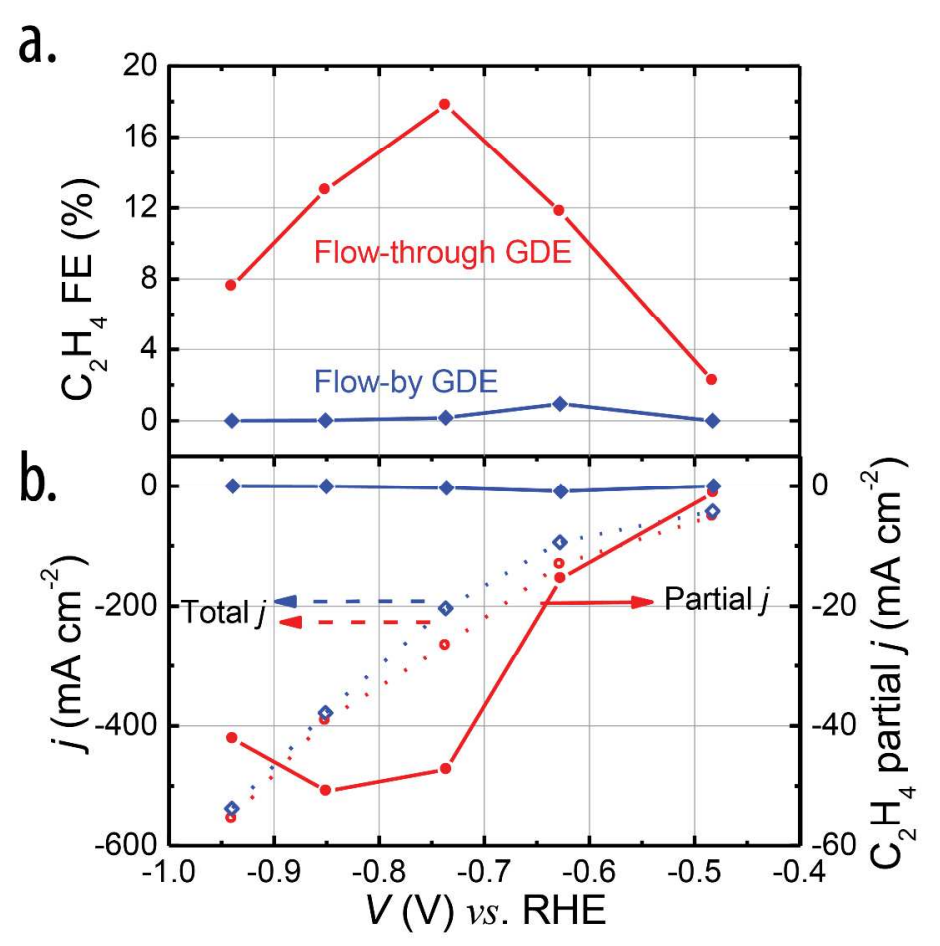

Figure 5. (a) FE for COR to $\mathrm{C}_{2} \mathrm{H}_{4}$ as a function of the applied potential for the flow-through configuration and the flow-by configuration. (b) The total operating current density (dotted curves, left $y$-axis) and the partial current density for $\mathrm{COR}$ to $\mathrm{C}_{2} \mathrm{H}_{4}$ (solid curves, right $y$-axis) as a function of applied potential for the flow-through configuration (red) and the flow-by configuration (blue). Both GDE configurations were operated in pH $15 \mathrm{KOH}$ electrolyte at -15 ${ }^{\circ} \mathrm{C}$, and the potential was compensated by IR drop measurement. 

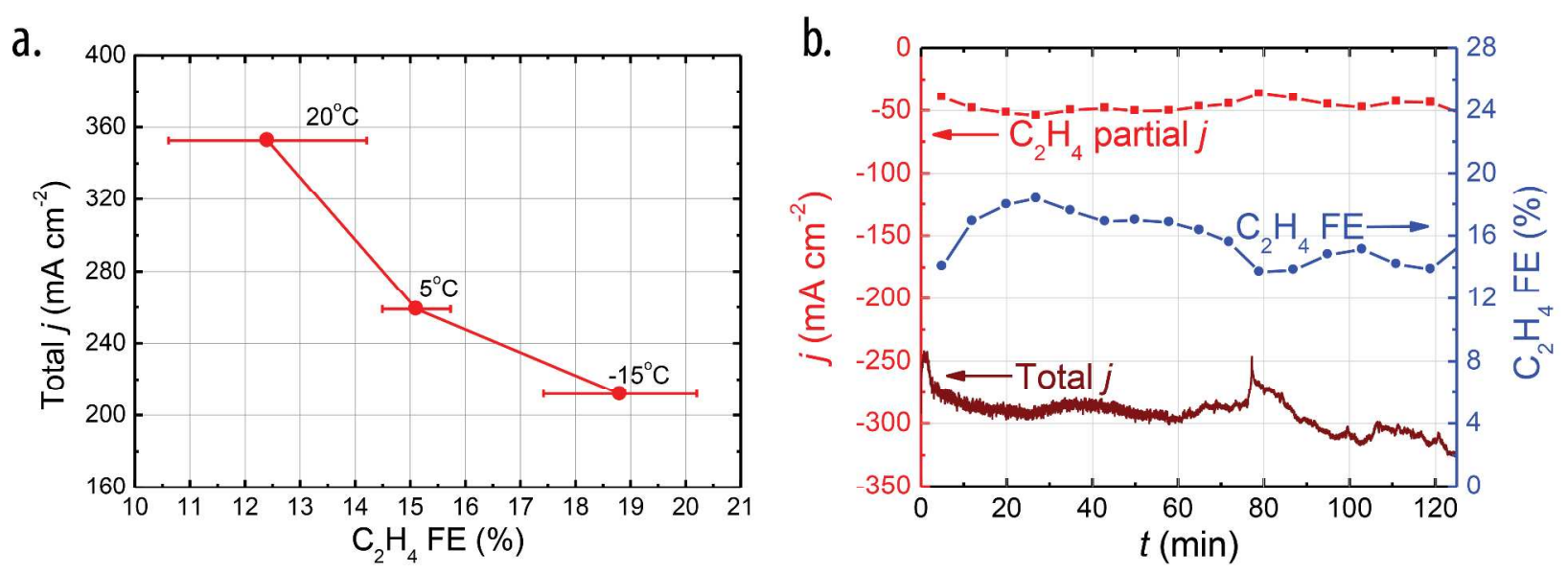

Figure 6. (a) The total operating current density and FE for $\mathrm{COR}$ to $\mathrm{C}_{2} \mathrm{H}_{4}$ for three different operating temperatures when the GDE materials in the flow-through configuration was poised at $-2.0 \mathrm{~V} v s . \mathrm{Ag} / \mathrm{AgCl}$ (the IR-corrected potentials at three different temperatures were quite similar, $-0.80 \pm 0.02 \mathrm{~V} v s$. RHE) in $10 \mathrm{M} \mathrm{KOH}$. (b) The total and $\mathrm{C}_{2} \mathrm{H}_{4}$ partial current density (left $y$-axis) and the $\mathrm{FE}$ (right $y$-axis) of $\mathrm{C}_{2} \mathrm{H}_{4}$ generation as a function of the operating time when the GDE materials in the flow-through configuration was poised at $-2.0 \mathrm{~V} v s$. $\mathrm{Ag} / \mathrm{AgCl}(-0.78 \mathrm{~V} v s$. RHE with IR-correction) in $10 \mathrm{M} \mathrm{KOH}$ at $-15^{\circ} \mathrm{C}$. 


\section{ACKNOWLEDGMENT}

This material is based upon work performed by the Joint Center for Artificial Photosynthesis, a DOE Energy Innovation Hub, supported through the Office of Science of the U.S. Department of Energy under Award Number DE-SC0004993. The authors also acknowledge the experimental assistance from Xinghao Zhou, Dr. Hsiang-Yun Chen, Dr. Yungchieh Lai and Dr. Bruce S. Brunschwig.

\section{Supporting Information}

The Supporting Information is available free of charge on the ACS Publications website at DOI: XXX, including: GDE fabrication procedures, GDE material characterization details, additional SEM and TEM images, cyclic voltammetry for flow-through and flow-by configurations, GC measurement optimization and calibration, calculation methods of FE, and the ECSA measurement method and results. 


\section{REFERENCES}

(1) Gattrell, M.; Gupta, N.; Co, A. A Review of the Aqueous Electrochemical Reduction of $\mathrm{CO}_{2}$ to Hydrocarbons at Copper. J. Electroanal. Chem. 2006, 594, 1-19.

(2) Ye, S.; Wang, R.; Wu, M.-Z.; Yuan, Y.-P. A Review on $\mathrm{G}_{-} \mathrm{C}_{3} \mathrm{~N}_{4}$ for Photocatalytic Water Splitting and $\mathrm{CO}_{2}$ Reduction. Graphene $C_{3} N_{4}$-Based Photocatal. 2015, 358, 15-27.

(3) Li, C. W.; Kanan, M. W. $\mathrm{CO}_{2}$ Reduction at Low Overpotential on Cu Electrodes Resulting from the Reduction of Thick $\mathrm{Cu}_{2} \mathrm{O}$ Films. J. Am. Chem. Soc. 2012, 134, 7231-7234.

(4) Lu, Q.; Rosen, J.; Zhou, Y.; Hutchings, G. S.; Kimmel, Y. C.; Chen, J. G.; Jiao, F. A Selective and Efficient Electrocatalyst for Carbon Dioxide Reduction. Nat. Commun. 2014, 5, 3242 .

(5) Adachi, K.; Ohta, K.; Mizuno, T. Photocatalytic Reduction of Carbon Dioxide to Hydrocarbon Using Copper-Loaded Titanium Dioxide. Sol. Energy 1994, 53, 187-190.

(6) Roberts, F. S.; Kuhl, K. P.; Nilsson, A. High Selectivity for Ethylene from Carbon Dioxide Reduction over Copper Nanocube Electrocatalysts. Angew. Chem. 2015, 127, $5268-5271$.

(7) Mistry, H.; Varela, A. S.; Bonifacio, C. S.; Zegkinoglou, I.; Sinev, I.; Choi, Y.-W.; Kisslinger, K.; Stach, E. A.; Yang, J. C.; Strasser, P.; Cuenya, B. R. Highly Selective Plasma-Activated Copper Catalysts for Carbon Dioxide Reduction to Ethylene. Nat. Commun. 2016, 7, 12123. 
(8) Asadi, M.; Kumar, B.; Behranginia, A.; Rosen, B. A.; Baskin, A.; Repnin, N.; Pisasale, D.; Phillips, P.; Zhu, W.; Haasch, R.; et al. Robust Carbon Dioxide Reduction on Molybdenum Disulphide Edges. Nat. Commun. 2014, 5, 4470.

(9) Cook, R. L.; MacDuff, R. C.; Sammells, A. F. On the Electrochemical Reduction of Carbon Dioxide at In Situ Electrodeposited Copper. J. Electrochem. Soc. 1988, 135, $1320-1326$.

(10) Jovanov, Z. P.; Hansen, H. A.; Varela, A. S.; Malacrida, P.; Peterson, A. A.; Nørskov, J. K.; Stephens, I. E. L.; Chorkendorff, I. Opportunities and Challenges in the Electrocatalysis of $\mathrm{CO}_{2}$ and $\mathrm{CO}$ Reduction Using Bifunctional Surfaces: A Theoretical and Experimental Study of $\mathrm{Au}-\mathrm{Cd}$ Alloys. Catal. $\mathrm{CO}_{2}$ Convers. Process. Fuels Small Mol. 2016, 343, 215-231.

(11) Jhong, H.-R.; Ma, S.; Kenis, P. J. Electrochemical Conversion of $\mathrm{CO}_{2}$ to Useful Chemicals: Current Status, Remaining Challenges, and Future Opportunities. Nanotechnol. Sep. Eng. 2013, 2, 191-199.

(12) Asadi, M.; Kim, K.; Liu, C.; Addepalli, A. V.; Abbasi, P.; Yasaei, P.; Phillips, P.; Behranginia, A.; Cerrato, J. M.; Haasch, R.; et al. Nanostructured Transition Metal Dichalcogenide Electrocatalysts for $\mathrm{CO}_{2}$ Reduction in Ionic Liquid. Science 2016, 353, 467.

(13) Rosen, B. A.; Salehi-Khojin, A.; Thorson, M. R.; Zhu, W.; Whipple, D. T.; Kenis, P. J. A.; Masel, R. I. Ionic Liquid-Mediated Selective Conversion of $\mathrm{CO}_{2}$ to $\mathrm{CO}$ at Low Overpotentials. Science 2011, 334, 643-644. 
(14) Zhou, X.; Liu, R.; Sun, K.; Chen, Y.; Verlage, E.; Francis, S. A.; Lewis, N. S.; Xiang, C. Solar-Driven Reduction of 1 Atm of $\mathrm{CO}_{2}$ to Formate at $10 \%$ Energy-Conversion Efficiency by Use of a $\mathrm{TiO}_{2}$-Protected III-V Tandem Photoanode in Conjunction with a Bipolar Membrane and a Pd/C Cathode. ACS Energy Lett. 2016, 1, 764-770.

(15) Chen, Y.; Lewis, N. S.; Xiang, C. Modeling and Simulation of the Spatial and LightIntensity Dependence of Product Distributions in an Integrated Photoelectrochemical $\mathrm{CO}_{2}$ Reduction System. ACS Energy Lett. 2016, 1, 273-280.

(16) Hashiba, H.; Weng, L.-C.; Chen, Y.; Sato, H. K.; Yotsuhashi, S.; Xiang, C.; Weber, A. Z. Effects of Electrolyte Buffer Capacity on Surface Reactant Species and the Reaction Rate of $\mathrm{CO}_{2}$ in Electrochemical $\mathrm{CO}_{2}$ Reduction. J. Phys. Chem. C 2018, 122, 3719-3726.

(17) Singh, M. R.; Clark, E. L.; Bell, A. T. Effects of Electrolyte, Catalyst, and Membrane Composition and Operating Conditions on the Performance of Solar-Driven Electrochemical Reduction of Carbon Dioxide. Phys. Chem. Chem. Phys. 2015, 17, $18924-18936$.

(18) Kortlever, R.; Shen, J.; Schouten, K. J. P.; Calle-Vallejo, F.; Koper, M. T. M. Catalysts and Reaction Pathways for the Electrochemical Reduction of Carbon Dioxide. J. Phys. Chem. Lett. 2015, 6, 4073-4082.

(19) Hori, Y.; Takahashi, R.; Yoshinami, Y.; Murata, A. Electrochemical Reduction of CO at a Copper Electrode. J. Phys. Chem. B 1997, 101, 7075-7081.

(20) Feng, X.; Jiang, K.; Fan, S.; Kanan, M. W. A Direct Grain-Boundary-Activity Correlation for CO Electroreduction on Cu Nanoparticles. ACS Cent. Sci. 2016, 2, 169-174. 
(21) Li, C. W.; Ciston, J.; Kanan, M. W. Electroreduction of Carbon Monoxide to Liquid Fuel on Oxide-Derived Nanocrystalline Copper. Nature 2014, 508, 504.

(22) Verdaguer-Casadevall, A.; Li, C. W.; Johansson, T. P.; Scott, S. B.; McKeown, J. T.; Kumar, M.; Stephens, I. E. L.; Kanan, M. W.; Chorkendorff, I. Probing the Active Surface Sites for CO Reduction on Oxide-Derived Copper Electrocatalysts. J. Am. Chem. Soc. 2015, 137, 9808-9811.

(23) Wu, K.; Birgersson, E.; Kim, B.; Kenis, P. J. A.; Karimi, I. A. Modeling and Experimental Validation of Electrochemical Reduction of $\mathrm{CO}_{2}$ to $\mathrm{CO}$ in a Microfluidic Cell. $J$. Electrochem. Soc. 2015, 162, F23-F32.

(24) Gupta, N.; Gattrell, M.; MacDougall, B. Calculation for the Cathode Surface Concentrations in the Electrochemical Reduction of $\mathrm{CO}_{2}$ in $\mathrm{KHCO}_{3}$ Solutions. J. Appl. Electrochem. 2006, 36, 161-172.

(25) Bard, A. J.; Inzelt, G.; Scholz, F. Electrochemical Dictionary: $2^{\text {nd }}$ Edition; Wiley: New York, 2002.

(26) Cook, R. L.; MacDuff, R. C.; Sammells, A. F. High Rate Gas Phase $\mathrm{CO}_{2}$ Reduction to Ethylene and Methane Using Gas Diffusion Electrodes. J. Electrochem. Soc. 1990, 137, $607-608$.

(27) Kopljar, D.; Inan, A.; Vindayer, P.; Wagner, N.; Klemm, E. Electrochemical Reduction of $\mathrm{CO}_{2}$ to Formate at High Current Density Using Gas Diffusion Electrodes. J. Appl. Electrochem. 2014, 44, 1107-1116. 
(28) Ogura, K.; Oohara, R.; Kudo, Y. Reduction of $\mathrm{CO}_{2}$ to Ethylene at Three-Phase Interface Effects of Electrode Substrate and Catalytic Coating. J. Electrochem. Soc. 2005, 152, 213219.

(29) Ogura, K.; Endo, N. Electrochemical Reduction of $\mathrm{CO}_{2}$ with a Functional Gas-Diffusion Electrode in Aqueous Solutions with and without Propylene Carbonate. J. Electrochem. Soc. 1999, 146, 3736-3740.

(30) Ogura, K.; Yano, H.; Shirai, F. Catalytic Reduction of $\mathrm{CO}_{2}$ to Ethylene by Electrolysis at a Three-Phase Interface. J. Electrochem. Soc. 2003, 150, D163-D168.

(31) Yano, H.; Shirai, F.; Nakayama, M.; Ogura, K. Efficient Electrochemical Conversion of $\mathrm{CO}_{2}$ to $\mathrm{CO}, \mathrm{C}_{2} \mathrm{H}_{4}$ and $\mathrm{CH}_{4}$ at a Three-Phase Interface on a $\mathrm{Cu}$ Net Electrode in Acidic Solution. J. Electroanal. Chem. 2002, 519, 93-100.

(32) Kim, B.; Ma, S.; Molly Jhong, H.-R.; Kenis, P. J. A. Influence of Dilute Feed and PH on Electrochemical Reduction of $\mathrm{CO}_{2}$ to $\mathrm{CO}$ on $\mathrm{Ag}$ in a Continuous Flow Electrolyzer. Electrochimica Acta 2015, 166, 271-276.

(33) Ma, S.; Luo, R.; Moniri, S.; Lan, Y.; Kenis, P. J. A. Efficient Electrochemical Flow System with Improved Anode for the Conversion of $\mathrm{CO}_{2}$ to CO. J. Electrochem. Soc. 2014, 161, F1124-F1131.

(34) Whipple, D. T.; Kenis, P. J. A. Prospects of $\mathrm{CO}_{2}$ Utilization via Direct Heterogeneous Electrochemical Reduction. J. Phys. Chem. Lett. 2010, 1, 3451-3458. 
(35) Thorson, M. R.; Siil, K. I.; Kenis, P. J. A. Effect of Cations on the Electrochemical Conversion of $\mathrm{CO}_{2}$ to CO. J. Electrochem. Soc. 2013, 160, F69-F74.

(36) Tornow, C. E.; Thorson, M. R.; Ma, S.; Gewirth, A. A.; Kenis, P. J. A. Nitrogen-Based Catalysts for the Electrochemical Reduction of $\mathrm{CO}_{2}$ to CO. J. Am. Chem. Soc. 2012, 134, $19520-19523$.

(37) Ma, S.; Sadakiyo, M.; Luo, R.; Heima, M.; Yamauchi, M.; Kenis, P. J. A. One-Step Electrosynthesis of Ethylene and Ethanol from $\mathrm{CO}_{2}$ in an Alkaline Electrolyzer. J. Power Sources 2016, 301, 219-228.

(38) Hoang, T. T. H.; Ma, S.; Gold, J. I.; Kenis, P. J. A.; Gewirth, A. A. Nanoporous Copper Films by Additive-Controlled Electrodeposition: $\mathrm{CO}_{2}$ Reduction Catalysis. ACS Catal. 2017, 7, 3313-3321.

(39) Prakash, G. K. S.; Viva, F. A.; Olah, G. A. Electrochemical Reduction of $\mathrm{CO}_{2}$ over SnNafion ${ }^{\circledR}$ Coated Electrode for a Fuel-Cell-like Device. J. Power Sources 2013, 223, 6873.

(40) Gutmann, F.; Murphy, O. J. Modern Aspects of Electrochemistry; Plenum Press: New York: New York, 1983.

(41) Zeng, K.; Zhang, D. Recent Progress in Alkaline Water Electrolysis for Hydrogen Production and Applications. Prog. Energy Combust. Sci. 2010, 36, 307-326. 
(42) Kuhl, K. P.; Cave, E. R.; Abram, D. N.; Jaramillo, T. F. New Insights into the Electrochemical Reduction of Carbon Dioxide on Metallic Copper Surfaces. Energy Environ. Sci. 2012, 5, 7050-7059.

(43) Hori, Y.; Kikuchi, K.; Suzuki, S. Production of $\mathrm{CO}$ and $\mathrm{CH}_{4}$ in Electrochemical Reduction of $\mathrm{CO}_{2}$ at Metal Electrodes in Aqueous Hydrogencarbonate Solution. Chem. Lett. 1985, $14,1695-1698$.

(44) McCrory, C. C. L.; Jung, S.; Ferrer, I. M.; Chatman, S. M.; Peters, J. C.; Jaramillo, T. F. Benchmarking Hydrogen Evolving Reaction and Oxygen Evolving Reaction Electrocatalysts for Solar Water Splitting Devices. J. Am. Chem. Soc. 2015, 137, 43474357. 